\title{
Cardiac Abnormalities in Chronic Alcoholism
}

\section{An Evidence Suggesting Association of Myocardial \\ Abnormality with Chronic Alcoholism in 107 \\ Japanese Patients Admitted to a \\ Psychiatric Ward}

\author{
Tadashi KoIde, M.D., * Kikuo Machida, M.D., ${ }^{\dagger}$ \\ Atsuo Nakanishi, M.D., ${ }^{*}$ Katsuhiko Ozeki, M.D., ${ }^{*}$ \\ Saburo Mashima, M.D., * and Hiroaki Kono, M.D.**
}

\section{SuMMARY}

The incidence of cardiac abnormalities was studied in 107 cases with chronic alcoholism, admitted to a psychiatric ward. More than half of them adhered to drink Japanese sake almost exclusively.

Either palpitation or shortness of breath was seen in 49 cases, cardiothoracic ratio was more than 0.50 in 15 of the 78 cases examined, and abnormal ECG was obtained in 65 of the 103 cases.

Among ECG abnormalities, broad and tall $P_{11}$, high $R_{V_{3}}$, high $T$ in leads $V_{2}$ and $V_{3}$ and QT prolongation were the most frequent. Various arrhythmias and conduction disturbances were also seen.

The clinical picture suggested more than incidental association of diffuse myocardial involvement with chronic alcoholism.

\section{Additional Indexing Words :}

Alcoholic cardiomyopathy Primary cardiomyopathy

$7 \mathrm{HE}$ concept of alcoholic cardiomyopathy has been mentioned in western 1 literature since the end of the last century. ${ }^{1)}$ It is, however, based only on the observation that the number of heavy drinkers in patients with primary cardiomyopathy is unproportionately large when compared to the general population. ${ }^{2}$ This was apparently true in some western reports on this subject, ${ }^{3)}$ but was not clear in our study on Japanese patients. ${ }^{4}$ We should not base solely on this kind of observation for establishment of a concept, since

* The Second Department of Internal Medicine, Faculty of Medicine, University of Tokyo, Tokyo.

† Present Address: Department of Radiology, Faculty of Medicine, University of Tokyo Branch Hospital, Tokyo.

** Department of Psychiatrics, Kurihama National Sanatorium, Yokosuka.

This work was supported in part by the special research grant for medical science from the $\mathrm{Mi}_{\mathrm{i}}$ istry of Welfare, Japan.

Received for publication July 25, 1972. 
the percent of heavy drinkers in general population depends on the society examined.

The clinical picture of heavy drinkers is usually not characteristic among patients with primary cardiomyopathy and the diagnosis depends on daily amount of alcohol consumed and on duration of drinking history, of which the harmless limit is set empirically and rather arbitrarily without definite scientific basis. Reported cases were, hitherto, mainly from western countries except for a few from Asia. ${ }^{4), 5)}$ Since causal relation of alcohol to chronic myocardial disease has not been proved, ingredients of alcoholic beverages other than alcohol could be the real toxic agents as cobalt in beer. ${ }^{6)}$ Associated nutritional deficiency, liver disease and other metabolic disorders also may play roles.

Nevertheless, alcoholic cardiomyopathy has been suspected to be the commonest type of primary cardiomyopathy in a society. " Also it was claimed that thése patients included not only skid-rows but many executives. ${ }^{7)}$ If these are true, the disease proposes a problem on such society, which is sociological as well as medical and of more than academic interest.

In respect of possible urgency of the problem, the present study was done to elucidate, if cardiac abnormalities were significantly more frequent in heavy drinkers than in general population in Japan.

\section{Clinical Materials}

One hundred and seven male patients were selected from 137 cases admitted to the Kurihama National Sanatorium for correction of alcohol addiction. The reason of exclusion of 30 cases was their having significant cardiovascular or pulmonary diseases of known entities: systemic hypertension of equal to or more than 160 systolic or 90 diastolic in 21, major pulmonary involvement with tuberculosis in 5 (with systemic hypertension in 1), myocardial infarction with or without hypertension in 2 , rheumatic mitral valvular disease in $\mathbf{l}$ and anemia with a hemoglobin level less than $12 \mathrm{Gm} . / 100 \mathrm{ml}$. in 1 .

Age of the patients ranged from 24 to 65 (average 40.8 ) years, but $85 \%$ of the cases were between 30 and 49 years (Table I). The drinking period before hospitalization was documented by 103 patients. It distributed widely from 2 to 46 years, but was longer than 10 years in 84 cases $(82 \%$ ) (Table II). Less than 6 years' duration was in only $3(3 \%)$. The choice of alcoholic beverages was informed by 102 patients. Fifty-nine cases $(55 \%)$ used to drink mainly Japanese sake, while other

Table I. Age Distribution of the 107 Pationts with Chronic Alcoholism

\begin{tabular}{c|c|c|c|c|c}
\hline Age (yrs.) & $20-29$ & $30-39$ & $40-49$ & $50-59$ & $60-69$ \\
\hline No. of cases & 5 & 44 & 47 & 10 & 1 \\
\hline$\%$ & 4.6 & 41.1 & 43.9 & 9.3 & 0.9
\end{tabular}


Table II. History of Drinking Alcoholic Beverages in 107 Patients

\begin{tabular}{c|c|c|c|c|c|c|c|c|c|c|c}
\hline $\begin{array}{c}\text { Length of history } \\
\text { (yrs.) }\end{array}$ & $0-5$ & $6-10$ & $11-15$ & $16-20$ & $21-25$ & $26-30$ & $31-35$ & $36-40$ & $41-45$ & $46-50$ & Unknown \\
\hline No. of cases & 3 & 16 & 18 & 31 & 17 & 10 & 7 & 0 & 0 & 1 & 4 \\
\hline$\%$ & 2.9 & 15.5 & 17.4 & 30.0 & 16.5 & 9.7 & 6.7 & 0 & 0 & 0.9 & - \\
\hline
\end{tabular}

favored liquors were whiskey in 17, shochu (Japanese distilled siprits from rice or other sources of starch) in 8 , and beer in 1. Other 17 cases did not adhere to any one favorite. Significant amount of beer (more than $2 \mathrm{~L}$. daily) was taken by only 7 patients. Average daily amount of ethanol, taken during a few years before hospitalization, was calculated roughly from amount of various liquors on patients' documentation and median figures of their ethanol content. ${ }^{8)}$ It was less than 125 $\mathrm{ml}$. of ethanol (900 ml. as Japanese sake) in 21 (21\%), between 125 and $200 \mathrm{ml}$. in $51(50 \%)$ and more in 30 cases $(29 \%)$.

Physical examination by the cardiologists was done in 78 cases within 82 days after admission (30.8 days on average, and between 15 and 60 days in 58 of them). This period usually indicates the period of abstinence from alcohol. Chest X-ray and ECG were taken within 2 weeks after admission.

\section{Results}

History:

Heart disease of unknown etiology was diagnosed before hospitalization in only one patient. Other cardiovascular abnormalities known in the history were single cases of situs inversus totalis, temporary systolic hypertension and " angina pectoris". The last case may have coronary artery disease, but his symptoms and ECG findings were not characteristic as classical angina. Pulmonary diseases were diagnosed in 10 (tuberculosis in 7 and pneumonia in 3).

Liver diseases were frequent in documentation by patients. These were cirrhosis in 7, hepatitis in 6 and unspecified in 17 . Other complications were gastrointestinal upsets in 28 (including gastroduodenal ulcer in 13), diabetes mellitus in 6, neuralgia in 5, renal diseases in 3, beriberi in 1 and sepsis in 1 .

Table III. Incidence of Major Cardiovascular Symptoms in 100 Cases

\begin{tabular}{l|c|c|c}
\hline \multicolumn{1}{c|}{ Symptoms } & At rest & On exercise & Total \\
\hline Palpitation & 9 & 35 & 44 \\
\hline Shortness of breath & 10 & 26 & 36 \\
\hline Dizziness & $24^{*}$ & 10 & 34 \\
\hline Chest pain & 13 & 14 & 27 \\
\hline Leg edema & - & - & 20
\end{tabular}

* Orthostatic 
Symptoms and signs:

Several frequent cardiovascular symptoms were shown in Table III. Either palpitation or shortness of breath was seen in 49 cases. Duration of drinking period before development of these symptoms distributed widely (Table IV). It may be worth to note that a substantial number of cases developed symptoms within a relatively short period (2-5 years) of heavy alcohol intake. During periods of abstinence from alcohol, palpitation and shortness of breath decreased in 29, but unchanged in 18 cases (Table V). This kind of information was unavailable in other 2 . Seven patients with unchanged symptom had been followed up for at least 1 month, suggesting the chronic nature of their symptoms.

Among other cardiovascular symptoms, orthostatic dizziness or syncope was frequent, but not considered as Stokes-Adams syndrome from the clinical picture and course. Chest pain was vague, non-specific and not typical of angina pectoris in most of the cases. Neuralgia and myalgia were likely to be included in this category, but precise diagnosis was difficult in many cases and hence all patients with chest pain were combined together. Leg edema was not necessarily a cardiac symptom since liver disease and hypoalbuminemia were frequent. Atrial fibrillation was seen in one case. Another case had experienced several bouts of non-exertional regular tachycardia with abrupt onset and cessation, which began after 5 years of alcohol drinking. Severe

Table IV. Period of Drinking and Palpitation or Shortness of Breath

\begin{tabular}{lccc|c|c|c|c|c|c|c|c|c|c}
\hline 1. Drinking period (yrs.) & $46-55$ & $41-45$ & $36-40$ & $31-35$ & $26-30$ & $21-25$ & $16-20$ & $11-15$ & $6-10$ & $0-5$ \\
\hline 2. Total no. of cases & 1 & 0 & 0 & 6 & 9 & 17 & 29 & 17 & 15 & 3 \\
\hline 3. Cumulative no. of cases & 1 & 1 & 1 & 7 & 16 & 33 & 62 & 79 & 94 & 97 \\
\hline 4. No. of symptomatic cases & 0 & 0 & 0 & 4 & 4 & 6 & 10 & 9 & 10 & 2 \\
\hline 5. Development of symptoms* & 0 & 0 & 0 & 2 & 1 & 0 & 11 & 7 & 11 & 12 \\
\hline 6. \% of 4 in 2 & 0 & 0 & 0 & 66.7 & 44.4 & 35.3 & 34.5 & 52.9 & 66.7 & 66.7 \\
\hline 7. \% of 5 in 3 & 0 & 0 & 0 & 28.6 & 6.3 & 0 & 17.7 & 8.9 & 11.7 & 12.4
\end{tabular}

* Number of cases in which palpitation or shortness of breath developed at this period of drinking history.

Table V. Palpitation and Shortness of Breath after Abstinence from Alcohol

\begin{tabular}{l|c|c|c|c|c|c|c}
\hline Period of abstinence & $\begin{array}{c}\text { Up to } \\
7 \text { days }\end{array}$ & $\begin{array}{c}8-14 \\
\text { days }\end{array}$ & $\begin{array}{c}15-31 \\
\text { days }\end{array}$ & $\begin{array}{c}32 \text { days- } \\
3 \text { months }\end{array}$ & $\begin{array}{c}4-6 \\
\text { months }\end{array}$ & Unclear & Total \\
\hline Cases with unchanged symptoms & 2 & 0 & 6 & 5 & 2 & 3 & 18 \\
\hline Cases with reduced symptoms & 2 & 5 & 11 & 5 & 1 & 5 & 29
\end{tabular}


symptoms of heart failure, including orthopnea, paroxysmal nocturnal dyspnea, productive cough and bloody sputum, were not seen.

Non-cardiovascular symptoms were also common. These included hand tremor in 54, abdominal fullness in 42, abdominal pain in 31 and anorexia in 30 .

Physical examination by the cardiologists after periods of abstinence revealed apparently healthy and moderately nourished men. Inspection in these 78 patients was not impressive except for one subicteric case. Heart rate was faster than 100 in 4 and slower than 60 in 6 . All patients were normotensive, although 7 of them had a pressure equal to or higher than 90 diastolic, with or without systolic hypertension of higher than 160, immediately after admission. These cases were included in this study because of temporary nature of the hypertension. On cautious auscultation, apical third sound was audible in 37, and the fourth sound in 4. Pulmonary râles were heard in 2. Liver was palpable in 29 and was more than $1 \mathrm{~cm}$. in 12 of them. Pretibial

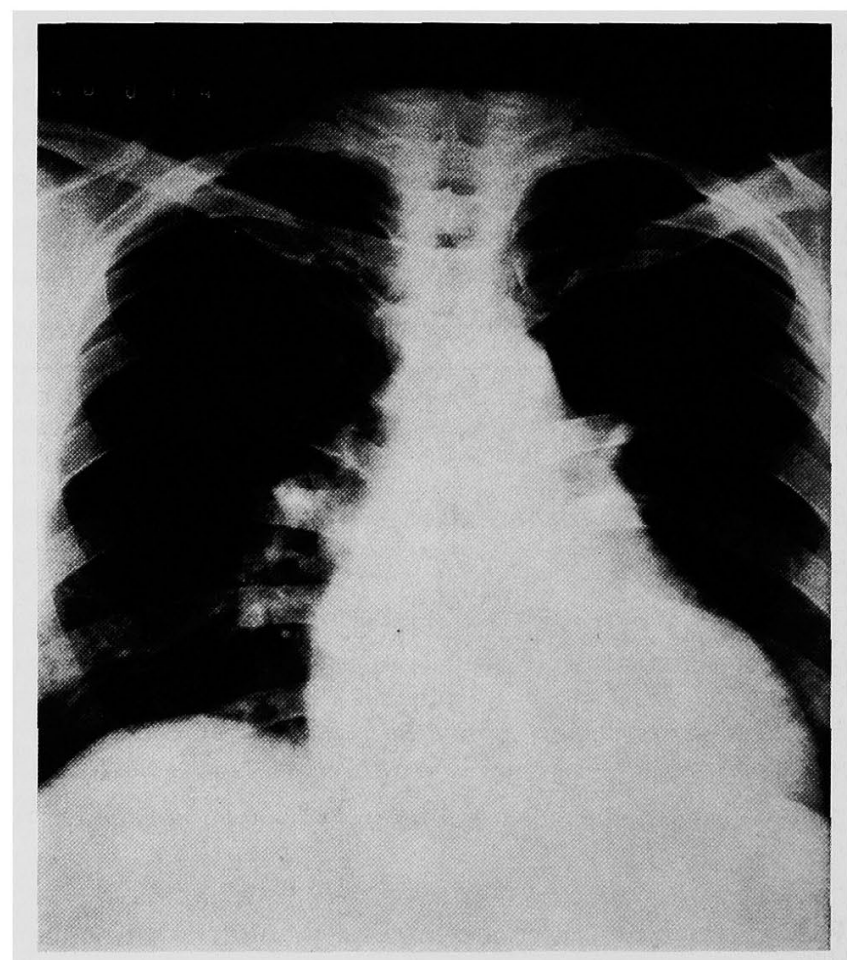

Fig. 1. X-ray suggestive of generalized cardiac enlargement. This film was taken 2 days after admission in a 33-year-old male. He had taken $1,800-2,700 \mathrm{ml}$. of Japanese sake (250-380 ml. of ethanol) daily for the most of his alcoholic period, which began from his 22 years of age. The diagnosis of heart disease was made before his last admission, but its relation to alcoholism had been ignored. 
Table VI. ECG Abnormalities in 103 Cases

\begin{tabular}{|c|c|}
\hline Abnormality & Number of cases \\
\hline Sinus tachycardia (heart rate $>100$ ) & 2 \\
\hline Sinus bradycardia (heart rate $<60$ ) & 23 \\
\hline Coronary sinus rhythm & 2 \\
\hline Frequent PAC & 1 \\
\hline Frequent PVG & 1 \\
\hline Atrial fibrillation with tachycardia & 1 \\
\hline WPW syndrome & 1 \\
\hline $\mathrm{PQ}$ prolongation $(\geq 0.22 \mathrm{sec}$.) & 2 \\
\hline$P_{\text {II }}$ high voltage & 16 \\
\hline Broad $P_{I I}$ & 13 \\
\hline Left axis deviation $\left(\geq-30^{\circ}\right)$ & 4 \\
\hline IRBBB & 2 \\
\hline $\mathrm{R}_{\mathrm{V} \perp}$ high voltage & 4 \\
\hline $\mathrm{R}_{\mathrm{V}_{3}}$ high voltage & 28 \\
\hline ST depression & 1 \\
\hline $\boldsymbol{T}_{\mathrm{V} 2 \cdot v_{3}}$ high voltage & 13 \\
\hline Other $\mathrm{T}$ abnormalities & 11 \\
\hline $\mathrm{QT}_{\mathrm{c}}>0.42 \mathrm{sec}$ & 40 \\
\hline Normal ECG & 38 \\
\hline
\end{tabular}

edema was observed in one, but ascites in none.

Chest $X$-ray and ECG:

Chest X-ray was available in 79 patients. Cardiothoracic ratio exceeded 0.50 in 15 of them. Left ventricular, and sometimes also right atrial, enlargement was suggested on posteroanterior projection (Fig. 1). Pulmonary congestion was not demonstrated in any of them.

Incidences of various EGG abnormalities shown in Table VI. Wide $P$ and high voltages of $P, R$ and $T$ waves were diagnosed when the value exceeded the mean in age-matched normal male Japanese by more than 2 SD. 9) Sinus bradycardia, high voltages of $P_{I I}, R_{V_{5}}$ and $T_{V_{2}, V_{3}}$, wide $P_{I I}$ and QT prolongation were frequent. $T$ abnormalities other than high voltage included flat or inverted $T$ in 9 (leads $I$ and ${ }_{a} V_{L}$ in 5 , left precordial in 4 and $\mathrm{aV}_{\mathrm{F}}$ and $\mathrm{V}_{1-3}$ in 1 ) and notched $\mathrm{T}$ in 3 . Prominent $U$ in leads $\mathrm{V}_{2-3}$ was also frequent. It sometimes overlapped on $\mathrm{T}$ and gave an impression of bifid $\mathrm{T}$. The $\mathrm{S}_{\mathrm{II} \cdot \mathrm{III}}$ pattern with less than $-30^{\circ}$ left axis deviation was also frequent, although not listed in the table. Normal ECG was recorded in only 38 cases, even when the upper 3 items in the Table VI were not considered as abnormal.

Several ECG measurements were compared to those in normal male Japanese of corresponding age (Table VII). Average voltages of $P_{11}, R_{V 5}$ and 
Table VII. Comparison of ECG Measurements between Normal and Alcoholic Japanese Males of Comparable Age

\begin{tabular}{|c|c|c|c|c|}
\hline ECG measurement & Age (yrs.) & Alcoholic $\mathrm{m} \pm \mathrm{SD}(\mathrm{N})$ & Normal $\mathrm{m} \pm \mathrm{SD}(\mathrm{N})$ & $\mathrm{P}$ \\
\hline \multirow{2}{*}{$P_{I I}$ duration (sec.) } & $30-39$ & $0.107 \pm 0.010$ & $0.097 \pm 0.019$ & $\angle 0.01$ \\
\hline & $40-49$ & $0.112 \pm 0.013(46)$ & $0.095 \pm 0.016(153)$ & $\angle 0.01$ \\
\hline \multirow{2}{*}{$P_{I I}$ voltage $(\mathrm{mV})$} & $30-39$ & $0.116 \pm 0.037$ & $0.096 \pm 0.046$ & $\angle 0.01$ \\
\hline & $40-49$ & $0.113 \pm 0.050$ & $0.100 \pm 0.024$ & $\angle 0.01$ \\
\hline \multirow{2}{*}{$\mathbf{R}_{V_{5}}$ voltage $(\mathrm{mV})}$. & $30-39$ & $2.467 \pm 0.817(42)$ & $1.585 \pm 0.629(119)$ & $\angle 0.01$ \\
\hline & $40-49$ & $2.487 \pm 0.794 \quad(46)$ & $1.645 \pm 0.609$ & $\angle 0.01$ \\
\hline \multirow{2}{*}{$\mathrm{T}_{\mathrm{v}_{2}}$ voltage $(\mathrm{mV})}$. & $30-39$ & $0.941 \pm 0.435$ & $0.690 \pm 0.357 \quad(119)$ & $\angle 0.01$ \\
\hline & $40-49$ & $0.855 \pm 0.295 \quad(46)$ & $0.648 \pm 0.304$ & $\angle 0.01$ \\
\hline \multirow{2}{*}{$\mathrm{U}_{\mathrm{V} 2}$ voltage $(\mathrm{mV})}$. & $30-39$ & 0.098 & 0.066 & \\
\hline & $40-49$ & 0.089 & 0.072 & \\
\hline
\end{tabular}

$\mathrm{T}_{\mathrm{V} 2}$ and average duration of $\mathrm{P}_{\mathrm{II}}$ were significantly higher or longer than in control Japanese ${ }^{9 \prime}(\mathrm{P}<0.01)$.

Correlation of cardiovascular abnormalities with various factors:

The incidences of X-ray and ECG abnormalities were correlated to daily alcohol consumption, and to the kind of favorite liquor (Table VIII). In those who adhered to Japanese sake, the incidences of cardiomegaly and R, T and QT abnormalities increased with increasing amount of daily ethanol. When the incidence of QT prolongation was compared between less heavy $(<125 \mathrm{ml}$. ethanol) and ultraheavy $(200 \mathrm{ml}$.<ethanol) drinkers, the difference

Table VIII. Cardiac Abnormalities and Daily Alcohol Consumption*

\begin{tabular}{|c|c|c|c|c|c|c|c|c|}
\hline \multirow{2}{*}{$\begin{array}{l}\text { Type os liquor } \\
\text { Daily amount } \\
\text { of alcohol (ml.) }\end{array}$} & \multicolumn{4}{|c|}{ Japancse sake } & \multicolumn{4}{|c|}{ Others } \\
\hline & $\angle 125$ & $125-200$ & $200 \angle$ & Total & $\angle 125$ & $125-200$ & $200 \angle$ & Total \\
\hline $\mathrm{C} / \mathrm{T}>0.50$ & $2 / 15(13.3)$ & $4 / 20(20.0)$ & $3 / 12(25.0)$ & $9 / 47(19.1)$ & $0 / 2(0.0)$ & $2 / 13(15.4)$ & $3 / 13(23.1)$ & $5 / 28(17.9)$ \\
\hline Wide $P_{I I}$ & $1 / 19(5.3)$ & $4 / 25(16.0)$ & $1 / 14(7.1)$ & $6 / 58(10.3)$ & $1 / 2(50.0)$ & $4 / 21(19.0)$ & $0 / 21(0.0)$ & $5 / 38(13.2)$ \\
\hline 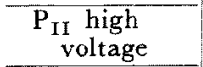 & $3 / 19(15,8)$ & $3 / 25(12.0)$ & $1 / 14(7.1)$ & $7 / 58(12.1)$ & $0 / 2(0.0)$ & $7 / 21(33.3)$ & $1 / 16(6.3)$ & $8 / 38(21.1)$ \\
\hline $\begin{array}{l}R_{V s} h i g h \\
\text { voltage }\end{array}$ & $5 / 19(26.3)$ & $8 / 25(32.0)$ & $5 / 14(35.7)$ & $18 / 58(31.0)$ & $0 / 2(0.0)$ & $7 / 21(33.3)^{5}$ & $3 / 16(18.8)$ & $10 / 38(26.3)$ \\
\hline $\begin{array}{c}\mathrm{T}_{\mathrm{V}_{2} \cdot \mathrm{v}_{3}} \mathrm{high} \\
\text { voltage }\end{array}$ & $2 / 19(10.5)$ & $3 / 25(12.0)$ & $3 / 14(21.4)$ & $8 / 58(13.8)$ & $0 / 2(0.0)$ & $2 / 21(9.5)$ & $2 / 16(12.5)$ & $4 / 38(10.5)$ \\
\hline $\begin{array}{c}\mathrm{QT}_{c}>0.42 \\
\text { sec.** }\end{array}$ & $5 / 19(26.3)$ & $8 / 25(32.0)$ & $9 / 14(64.3)$ & $22 / 58(37.9)$ & $1 / 2(50.0)$ & $7 / 21(33.3)$ & $5 / 16(31.3)$ & $13 / 3$ \\
\hline $\begin{array}{l}\text { * Number of } \\
\text { of ethanol } \\
\text { * The differe }\end{array}$ & $\begin{array}{l}\text { f cases w } \\
\text { consump } \\
\text { ence of ir }\end{array}$ & $\begin{array}{l}\text { h each abr } \\
\text { on. Num } \\
\text { cidence bet }\end{array}$ & $\begin{array}{l}\text { normality } \\
\text { erals in the } \\
\text { tween the }\end{array}$ & first and & over to & $\begin{array}{l}\text { I number o } \\
\% \text { of abnor } \\
\text { olumn was }\end{array}$ & $\begin{array}{l}\text { cas } \\
\text { rmal } \\
\text { sign }\end{array}$ & $\begin{array}{l}\text { th that } \\
\text { ( } P \measuredangle\end{array}$ \\
\hline
\end{tabular}


was significant statistically $(\mathrm{P}<0.04)$. On the contrary, the incidence of $\mathrm{P}$ changes did not parallel to alcohol intake. The incidence of abnormalities in the total cases was not significantly different between "sake drinkers" and others.

Cardiac enlargement was seen exclusively in patients with long history of alcohol drinking (equal to, or more than 10 years). Similarly, ECG abnormalities were seen after heavy drinking of 5 years or longer. There were, however, many cases with long history of alcoholism, but without objective signs of cardiac abnormality.

Since high voltage on ECG was a frequent observation, actual body weight of the patients was compared to their standard body weight. Deviation of the former from the latter was within $10 \%$ in $69.2 \%$ of the cases, more to the lighter side ( 15 to $25 \%$ ) in $21.3 \%$ and to the heavier side $(15$ to $40 \%$ ) in $9.6 \%$. Extent of this deviation did not correlate to high voltage.

Hypopotassemia, hypoalbuminemia and increased serum enzymes were frequent in our cases. No significant correlation was observed, however, between each one of these factors and incidence of various cardiac abnormalities.

\section{Discussion}

Our present study suggests the real presence of a kind of cardiac abnormality which is related to continuous intake of alcoholic beverages. Since all examinations were done after at least a few days of abstinence, the abnormality could not be indebted to the acute effect of alcohol. Lack of cases with severe congestive heart failure and giant cardiomegaly was natural, since patients with severe cardiac illness would usually be sent to cardiological wards, but not to psychiatric ones.

Clinical findings were, in general, similar to those reported in patients with alcoholic cardiomyopathy, and suggested a diffuse cardiomyopathy with insidious onset.4),10)-14) Minor differences were seen, however, between our present observations and those reported previously, which were presumably due to difference in severity of the disease. Some of them will be commented upon briefly.

Palpitation and exertional shortness of breath have been known as the frequent initial symptoms, ${ }^{11,13}$ ) but orthostatic dizziness has rarely been described. Whether this symptom was related to alcoholic involvement of autonomic nervous system or to direct effect of alcohol on cardiovascular system was obscure. Chest pain was reported to be rare by Evans, ${ }^{11)}$ but was present in many of our cases, as well as in one recent publication from Ceylon. ${ }^{5}$ ) The difference may be more terminological than real, since typical angina 
pectoris was not seen in our study.

Temporary hypertension was seen in 7 cases at the time of admission. Some of them had narrow pulse pressure, while others had wide pulse pressure with systolic hypertension. The former may be a sign of low-output cardiac failure ${ }^{13)}$ 14) and the latter may be related to hyperkinetic circulatory state of alcoholic beriberi. ${ }^{10), 11)}$ However, no clinical difference in cardiac state was seen between them.

A set of auscultatory findings, i.e. gallop rhythm, atrioventricular regurgitant murmur and pulmonary rales, has been frequently reported in alcoholic cardiomyopathy. $\left.\left.\left.\left.{ }^{10}\right), 11\right), 13\right), 14\right)$ In our patients, these signs were usually absent, except for frequently audible third heart sound. The incidence of the latter should not be stressed, since faintly audible third sound was an occasional finding in non-cardiac patients in our experience. Relative paucity of abnormal auscultatory finding could be understood on the basis of preselection of cases at the time of admission to the psychiatric ward.

QT prolongation was the most frequent abnormality on ECG. Frequent QT prolongation was suggested also by Burch et al. ${ }^{17)}$ Although the influence of serum electrolyte $\mathrm{e}^{18(-22)}$ and protein ${ }^{23,24)}$ changes on QT interval is known, the correlation of measured $Q T_{c}$ and either one of these serum abnormalities was insignificant in our present cases. The correlation might be obscured by the complicated combination of abnormalities in various serum factors.

Frequent observations suggestive of left ventricular and biatrial hypertrophy were in agreement with that reported in alcoholic cardiomyopathy. ${ }^{101,131,14)}$ Voltage abnormalities on ECG may be influenced by thickness of the chest wall and other properties of the thorax. Body constitution was, however, normal on physical examination in most of the cases, comparison of actual vs. standard body weights did not disclose an appreciable systematic deviation between them, and the individual deviation did not correlate to the ECG abnormalities. Another evidence of this line was the lack of correlation between $R$ and $T$ voltages. The association of both high voltages was seen in only 7 cases.

Evans had stressed the multiplicity of T wave changes on ECG and classified them into spinous, cloven, dimple and inverted $T .{ }^{11}$ High $T$ in our patients corresponded to the spinous $T$, but other types of $T$ changes were rare in our series. This contrasted to the observation of Burch ${ }^{10)}$ and Priest, ${ }^{12)}$ in which flat or negative $T$ was common. The discrepancy may reflect the mild cardiac involvement in our patients.

Alcoholic beverages are likely to cause cardiac involvement, irrespective of the kind of liquors. Our present observation shows clearly that the Japanese liquors are not free from cardiac toxicity, and the nature of cardic involvement 
is similar to that reported in western cases of alcoholic cardiomyopathy. The paucity of report on this subject from Japan is most likely due to our skepticism on the reality of this entity. Prevalence of heart diseases in beer or wine drinkers was suggested by some of the western physicians, ${ }^{11,13), 15), 16)}$ but was not clear in our cases.

The harmless limit of alcohol could not be set from this study. Among the 5 cases who used to take less than $80 \mathrm{Gm}$. of alcohol daily, only 2 had normal ECG. Whether this indicates the individual difference of susceptibility or residual abnormality due to excessive drinking in the past was obscure. Duration of heavy drinking may be important, however, since all 19 patients with less than 10 years' drinking history had normal-sized heart on X-ray, and none of the 3 patients with less than 5 years' drinking history had ECG abnormality.

\section{REFERENCES}

1. Walshe, W. H.: Diseases of the Heart and Great Vessels, 4th ed. London, 1873. Cited in Evans, W.: Brit. Heart J. 21 : 445, 1959.

2. Brest, A. N. and Moyer, J. H.: Cardiovascular Disorders, F. A. Davis Co., Philadelphia, 1968.

3. Massumi, R. A., Rios, J. C., Gooch, A. S., Nutter, D., DeVita, V. T., and Datlow, D. W.: Circulation 31 : $19,1965$.

4. Koide, T., Murao, S., Ito, I., Harumi, K., Yasuda, H., Sakamoto, T., Uozumi, Z., Sugishita, Y., Machida, K., Morooka, S., and Ueda, H.: Jap. Heart J. 12: 123, 1971.

5. Nagaratnam, N.: Cardiology 55: 41, 1970.

6. Symposium: Canad. Med. Assoc. J. 97: 881, 1967.

7. Burch, G. E. and DePasquale, N. P.: Circulation 42: A-47, 1970.

8. Kissin, B. and Begleiter, H.: The Biology of Alcoholism, Vol. 1, Plenum Press, New York, 1971.

9. The Committee on the Criteria of the Heart Disease and Electrocardiogram: Jap. Heart J. 4: $141,1963$.

10. Burch, G. E. and Walsh, J.J.: Am. J. Cardiol. 6: 864, 1960.

11. Evans, W.: Brit. Heart J. 21: 445, 1959.

12. Priest, R. G., Binns, J. K., and Kitchin, A. H.: Brit. Med. J. 2: 1454, 1966.

13. Alexander, C. S.: Am. J. Med. 41: 213, 1966.

14. Tobin, J. R., Jr., Driscoll, J. F., Lim, M. T., Sutton, G. G., Szanto, P. B., and Gunnar, R. M.: Circulation 35: 754, 1967.

15. Burch, G. E. and DePasquale, N. P.: Cardiologia 52: 48, 1968.

16. Amelung, D.: Dtsch. Med. Wschr. 95: 759, 1970.

17. Burch, G. E. and Giles, T. D.: Am. J. Med. 50: 141, 1971.

18. Surawicz, B. and Lepeschkin, E.: Circulation 8: 801, 1953.

19. Surawicz, B., Braun, H. A., Crum, W. B., Kemp, R. L., Wagner, S., and Bellet, S.: Circulation 16: 750, 1957.

20. Loeb, H. S., Pietras, R. J., Gunnar, R. M., and Tobin, J. R., Jr.: Circulation 37: 210, 1968.

21. Nagasaka, M., Yokosuka, H., Yamanaka, T., Sato, T., Nakamura, K., Kinouchi, T., Nagase, K., Shimizu, K., Seta, K., Yoshitoshi, Y., and Miyashita, H.: Jap. Heart J. 13: 187, 1972.

22. Weaver, W. F. and Burchell, H. B.: Circulation 21: 505, 1960.

23. Strasser, H., Märki, H. H., Wuhrmann, F., Niggli, S., and Wick, A.: Schweiz. Med. Wschr. 97: $46,1967$.

24. Wuhrmann, F. and Niggli, S.: Myocardosis, Charles C. Thomas Pub., Springfield, 1960. 